\title{
Implications of the Dominant Design in Electronic Initiation Systems in the South African Mining Industry
}

\author{
FRANCOIS C. SMIT and CARL W. I. PISTORIUS
}

\section{ABSTRACT}

This article analyzes an emerging technological innovation, namely, electronic initiation systems for mining explosives in South Africa. The concept of electronic initiation is presenting itself as a challenge to traditional initiation systems, particularly cap-and-fuse and shock tube technologies. From a technology strategy viewpoint, the challenge is to determine the nature of the managerial decisions that have to be addressed. The UtterbackAbernathy innovation model is used to assess the evolution of the emerging technology; it is found that the technology is still in the fluid phase and that a dominant design has not yet emerged. Since the dominant design is a very important milestone in the evolvement of the product with regard to both the technical and the business aspects, the immediate managerial focus should be on the evaluation factors that may influence the emergence of the dominant design. The emergence of a dominant design is, however, a complex process that depends on the interplay between a myriad of issues, including technological, market, social, economic, and related aspects. The paper anticipates the technological future of the innovation by exploring the factors that may influence the dominant design of electronic initiation systems, and casts the findings in a format that is useful for managerial decision support. () 1998 Elsevier Science Inc.

\section{Introduction}

The mining industry in South Africa, and gold mining in particular, has traditionally been one of the major contributors to the country's gross domestic product (GDP) as well a primary earner of foreign exchange. Gold, the mines, and in fact the entire mining industry are, however, experiencing increasing cost pressures. Even though the gold mining industry has always been extremely conservative in adopting technological innovations, economic, social, and political realities have brought a new focus on the impact of technology on productivity. It is against this backdrop that we consider the emergence of a technological innovation in the mining industry: specifically, electronic initiation systems for explosives.

FRANCOIS C. SMIT is with the Aerotek Division, CSIR, Pretoria, South Africa.

CARL W. I. PISTORIUS is professor in and director of the Institute for Technological Innovation, Faculty of Engineering, University of Pretoria, Pretoria, South Africa.

Address correspondence to Carl W. I. Pistorius, Institute for Technological Innovation, Faculty of Engineering, University of Pretoria, Pretoria 0002, South Africa. Fax: +27-12-362 5092; e-mail: <pistorius@ ee.up.ac.za>. 
Hundreds of thousands of blasting explosions are required daily in South African gold mines to extract the ore from the earth. Each of these explosive charges is typically in the order of 800 grams, and each charge requires its own detonator. The detonator forms part of a larger initiation system. Electronic initiation systems are a revolutionary development in the detonator industry and one that promises huge improvements to the mining industry with regard to cost, efficiency, productivity, safety, and reliability. An industry that is under intense cost pressures is very cost-sensitive to large-volume items such as initiators for detonation, and hence innovations in this area are of significant interest.

From a technology strategy viewpoint, the challenge is to determine the nature of the managerial decisions that have to be addressed in managing the emerging innovation. The Utterback-Abernathy (UA) model of innovation is used as a framework to assess the innovation process. This approach is useful in that it offers a structured way of considering the interaction between product and process innovations as a function of the maturity of the technology. The notion of a dominant design is a key element in the model. Once it has been determined that this innovation process follows the UA model, the model can be used to anticipate the subsequent development of the innovation. In this sense the general usefulness of the model can be exploited as a managerial decision-making aid to plot strategies in the phases that will necessarily ensue.

It is found that there is significant evidence to support the notion that the emerging electronic initiation systems are still in the pre-dominant design, fluid phase of the UA model. The importance of a dominant design is well known, with regard to its effect not only on the future evolvement of the technology, but also on the related market and business interests of the companies that will manufacture, use, and exploit that technology. At this stage of the innovation's evolvement, it is evident that the managerial focus should be on factors that will influence the transition from the fluid to the transitional phases of the model, and particularly on factors that may influence the emergence of the dominant design. The emergence of a dominant design is, however, a complex process that depends on the interplay between a myriad of issues, including technological, market, social, economic, and related aspects-there are no easy or set, cookbook-type answers. A major thrust of this investigation is thus to anticipate the technological future of the innovation by exploring factors that may influence the emergence of the dominant design.

To put the discussion on the innovation aspects of the new technology in perspective, it is appropriate to introduce the article by sketching the background to electronic initiation systems within the context of the South African mining industry. The defending mature detonator technologies are briefly discussed, namely, cap-and-fuse and shock tube, and the advantages of millisecond-accuracy blasting are then described, followed by a discussion of electronic initiation systems. Rival non-blasting technologies are briefly mentioned for the sake of completeness. In the second part of the article, the technology life cycle model and the notion of dominant design as applied to electronic initiation systems are investigated. The article is closed with conclusions about the future evolution of the technology, particularly with regard to factors that may influence the emergence of the new dominant design and thereby also the further evolvement of the technology and managerial decision making. The application of the UA model to this problem has also led to suggestions for the improvement of the model.

\section{The South African Mining Industry}

South Africa has one of the most impressive mineral industries in the world, with more than 60 minable minerals present in its soil. The extraction of many of these-such 
as gold, the platinum group minerals, manganese, chromium, vanadium, gem diamonds, zirconium, and andalusite - has put South Africa in a commanding position with respect to global production [1]. The mining industry plays a major role in the South African economy, having directly contributed $8 \%$ and indirectly contributed to $15 \%$ of the country's GDP in 1996. Employment in the mining industry represents a significant percentage of the country's total economically active population, particularly when one considers that each miner supports an average of seven to ten family members. It is clear that the mining industry is of prime economic and social importance to South Africa.

The mining industry can broadly be classified into two types of mining, namely, narrow-stope and open-cast mining. Narrow-stope mines, typically gold and platinum mines, are very deep underground mines. Open-cast mines are surface mines, typically quarries and coal and base metal mines. Since narrow-stope mining constitutes more than $75 \%$ of the South African detonator market, it is emphasized in this study.

Gold ore in South Africa is generally borne in reefs - thin rock layers seldom wider than one centimeter. Since it is impossible to extract only a vein of gold-rich ore, an area large enough for the miners to work in must be blasted. The blasting area, or stope, is a passage on the order of one meter high (called the stope width) that provides just enough space for a man to duck-walk or slide through. Because of the immense pressure from the rock above, the cavity left behind by mining would collapse in a few hours or days were it not for man-made supports that have to be inserted as the mining process progresses.

The working conditions down in the mines are very harsh. The stopes in which the miners work are narrow, poorly lit, and muddy and often have an inclination of up to $33^{\circ}$. The humidity level often reaches $100 \%$, while the temperature easily exceeds $35^{\circ} \mathrm{C}$. Other adverse underground conditions include hard, highly abrasive rock types and deep, highly stressed, and seismically active ground conditions [2]. In these conditions the miners have to drill into the rock face, for a single blast, in excess of a hundred holes that are between 1.6 and 1.8 meters deep. These holes are filled with explosives and interconnected with a series of detonators. When blasted, the rock shears away from the stope face and is thrown into a gully by the force of the blast. In this way the rock face is advanced by approximately one meter per day-also known as the rate of face advance.

There has been a strong recent decline in the profitability of the gold mining industry, mainly due to a decline in labor productivity (labor costs constitute $50 \%$ of total production costs), decreasing grades, rising production costs, and the declining price of gold. In the platinum industry it is clear that the lowest-cost producer will take the largest share of the market [3]. These pressures on the mines compel them to look at ways to increase profitability and productivity on all fronts. Although the gold mining industry in South Africa is traditionally very conservative in the adoption of new technology, these factors, together with the increased focus on safety, may not only lessen the resistance to implementing technological innovations, but in fact encourage the development and adoption of technological innovations.

\section{The Defending Mature Technologies: Cap-and-Fuse and Shock Tube Detonators}

Capped fuse and igniter cord, or cap-and-fuse as it is also often called, is the most widely used initiation system in South African gold mines, having captured more than $95 \%$ of the detonator market since its introduction in 1962. The fuse and igniter cord system consists of a series of caps (one in each hole) that are connected to the igniter cord (trunkline) with a safety fuse. To initiate a blast, the igniter cord is set alight, 
causing a flame that is referred to as the burning front. The explosives are ignited when the flame reaches the cap at the end of the safety fuse. The inter-hole delay is determined by the length of the igniter cord, while the in-hole delay is determined by the capped fuse. In many countries this system has long since lost popularity to shock tube systems because of its inherent timing inaccuracies and low reliability, as well as the safety risk associated with a burning igniter cord. Yet it has remained popular in South Africa because of its lower direct cost and the resistance in the mining industry to adopting new technologies.

Many view successful blasting with fuse and igniter cord as a black art. The accuracy and reliability of fuse and igniter cord systems are dependent on environmental factors such as temperature, humidity, and atmospheric pressure; on the age of the products; and also on the way in which the system is used [4]. Problems associated with the capand-fuse system include misfires (when a detonator doesn't set off the explosives) and out-of-sequence shots that result from the variability in burning speeds of the incendiary compounds used. The correct fuse length, igniter cord type, and inter-connector spacing are all critically important to balance the number of out-of-sequence shots and the burning front distance. The trade-off between strict sequential firing and a long burning front distance. The trade-off between strict sequential firing and a long burning front to avoid igniter cord cut-offs (when a flying piece of rock cuts off the igniter cord to the next detonator and thereby prevents it from firing) thus forms one of the fundamental limitations of the cap-and-fuse system. Furthermore, there is no method to non-destructively test the fuses and igniter cord, and it is therefore impossible to quickly detect incipient out-of-sequence shots, misfires, and short burning fronts once the system has been installed.

The shock tube initiation system is a non-electric millisecond-delay system comprising a length of shock tube with a detonator attached to one or both ends. The shock tube is a small-diameter tube internally coated with a thin layer of explosive compound. Upon initiation (by means of a detonator, detonating fuse, or similar explosive action), this explosive layer propagates a detonation along the inside of the tube at a speed of 2000 meters per second to the detonators attached to the ends of the tube [4]. The shock tubing itself does not explode and is not damaged by the propagation of the internal detonation, thus making for a safer system than the cap-and-fuse system, since there are no explosive side effects on the environment. Shock tube systems improve sequential firing, are easy to use, are quick to connect, and improve face advance significantly. They use accurate millisecond-delay detonators and offer substantial technical advantages over the capped fuse and igniter cord system. Further advantages include improved labor efficiencies; improved stope width control, resulting in improved grades; better working conditions; the elimination of the fire hazard; and a reduced overall cost of blasting, despite the increased cost of the detonator itself.

Some of the disadvantages of the shock tube system are that it takes a long time to establish the individual faces, with subsequent intensive and accurate planning; that crews must be retrained, which is time-consuming; and that supervision is critical to maintain strict standards. Misfires also cause problems because the rest of the detonators in a sequence will no longer be initiated if one detonator misfires. Another problem is that the inherent firing-time deviations of the pyrotechnic delay elements of the detonators are high enough to result in firing of out-of-sequence shots. One of the problems experienced with the fuse and igniter cord system that have not been resolved with shock tubes is that cut-off still happens because of flying pieces of rock. The probability 
of cut-off is, however, significantly less than for cap-and-fuse systems because of the detonation's faster rate of advance.

\section{The Attacking Emerging Technology: Electronic Initiation Systems}

Electronic initiation systems depart in a significant way from past practice. The detonation and timing subsystems are based on entirely different scientific and engineering principles than the previous technologies (cap-and-fuse and shock tube). The cost/benefit advantages that electronic initiation systems bring are significant and will improve even more as the technology is developed.

Although a variety of systems and hybrids are being developed, an electronic initiation system consists of a number of electronic detonators and is characterized externally by the use of a wire harness or loom for signal transmission, as well as a blast controller responsible for electronic testing and blasting protocol [5]. Internally, the detonators are characterized by a timing circuit and logic circuitry controlling firing timing. A storage capacitor is often used to supply operating power to the circuit as well as the energy needed for igniter firing. The heart of the electronic detonator is an electronic circuit, typically an integrated circuit (IC), that detonates the surrounding explosives in which it is embedded through the heating of a fuse fire or related mechanism.

Brinkmann [4] developed a set of general specifications with which an initiation system should comply to meet the requirements of blasting in the gold mines. These specifications include:

- Flexibility-The system should be such that it can easily be applied to all types of blasting on a gold mine, and the time delay between holes should be variable.

- Accuracy-All holes must fire in sequence, i.e., the timing period of adjacent holes must not overlap. The allowable out-of-sequence rate should be restricted to less than one in 100,000 .

- Reliability - The basic product reliability should be at least 100 times better than that of fuse and igniter cord, i.e., less than one failure in 100,000 units. To avoid cut-offs, the detonator units within all holes of a blast should be armed before the first hole fires. All elements of the initiation system should be capable of withstanding the rigorous working and environmental conditions in gold mines.

- Testability-A method of testing the initiation system is needed to verify the correct functioning of all elements after the system has been hooked up and before the miner leaves the blasting area. If faults do occur, they should be easily identified and quickly remedied.

- Ease of use-The system should be simple and straightforward to use.

- Safety-No unplanned detonations should occur. The system should be immune to accidental detonation during transportation, storage, and use, from such causes as static or stray electric currents, impact, friction, and flame.

The recent development of electronic initiation systems potentially threatens to change the entire detonator industry, since it adheres to the conditions set out above, whereas the mature initiation systems don't adhere in all respects. Electronic initiation systems provide flexible, millisecond-accuracy blasting combined with increased safety features, resulting in increased control of the blast and a significant increase in mining productivity. 
The advantages of an initiation system capable of delivering millisecond accuracy and sequential blasting are particularly important and hence warrant special mention. They include:

- Increased face advance

- Reduced stope width

- Improved rock fragmentation

- Improved muck pile distribution

- Improved hanging wall conditions

- Reduction in ground vibration and air blast

Although the prime advantage of electronic initiation systems over other systems is the millisecond-accuracy delay times obtainable, additional advantages include:

- Increased safety-Most systems have safety features incorporated in their design, making it virtually impossible to initiate a detonator with normal handling procedures. The detonators are not affected by flame or stray electric currents or signals.

- Reduced hazard-The danger of an open flame is eliminated. The probability of igniting timber stope supports is therefore greatly reduced.

- Reduction of the volume of noxious fumes-A significant amount of noxious fumes is produced by the burning of igniter cord and fuses and the explosives over the full blasting period. These fumes are lessened if electronic detonators are used.

- Increased control and flexibility -With certain systems, remote control—e.g., by a computer above the ground-is now possible. The various blasting needs of gold mines can also be better met.

- Reduction in the number of misfires-Because the integrity of the detonators can be checked before the blast is initiated, the number of misfires will be reduced.

- Less explosives are used - not only because of the increase in face advance, but also because of the increased efficiency that an accurately controlled blast with no out-of-sequence shots will bring.

- Less flying rock is produced.

- Cut-off not an issue-Because all detonators are self-powered after being armed, and all detonators are armed before the first one explodes, there is no danger that some detonators will not explode when flying rocks cut the connecting wires.

- Cost-effectiveness-Even though electronic detonators are much more expensive than fuse and igniter cord, it is a more cost-effective system than fuse and igniter cord because of its other advantages.

Despite all these advantages, a number of problems have also been experienced by the developers of electronic initiation systems. For example, problems have been experienced with the watertightness of the detonators in the very humid conditions underground. One manufacturer's detonator failed to operate correctly if a shadow fell on the IC in the detonator. It has also been found that the cables connecting the detonators to one another act as antennas, picking up electromagnetic interference that might lead to a misfire. Some manufacturers have experienced misfires because of the so-called piezoelectric effect; i.e., explosions during a blast cause mechanical stresses in the rock structure that result in the electric polarization of the rock. This may have an influence on the electronic circuitry of a detonator by causing stray currents if precautionary measures are not taken. 
It has also been reported that miners have sometimes reacted negatively to using a new detonator, to the extent that they may actually sabotage the trial tests by not connecting the detonators correctly or by damaging the detonator. Even with systems where the operation of the electronic detonator is remarkably similar to the old capand-fuse system, miners have had to be retrained and motivated to use the new system. Another problem, not technical but characteristic of many new and emerging technologies, is that electronic initiation systems are not yet as widely proven as either fuse and igniter cord or shock tube systems. Many of the benefits still have to be quantified and proven in a large number of blasts and in varying circumstances.

\section{Other Contending Technologies}

For the sake of completeness, it must be mentioned that in addition to electronic initiation systems, there are several other emerging technologies that may change the face of mining (so to speak). These include some revolutionary new non-blasting mining techniques.

Blasting damages the structural strength of rock, thereby increasing the risk of rock-burst. These rock bursts and falls are responsible for more than half the fatal and nonfatal injuries in gold mines. Hence blast-free mining technologies are attracting much interest. Without blasting there would be no fumes or handling of explosives. Apart from these advantages with regard to safety, nonexplosive mining methods also hold the promise of increased productivity by means of continuous mining, reducing the time lost during breaking the current cycle of drill, blast, and clean. The need to clear the face for a number of hours while waiting for the blast and the fumes to clear will also be eliminated [6].

Although blast-free technologies are not yet considered to be serious competitors to blasting (because of higher cost and lesser efficiency), the increase in focus in recent times on the safety of miners as well as the decrease in profitability of the whole gold mining industry might well lead to increased research and development and use of some of these methods. The most promising blast-free methods of mining include [7]:

- $\mathrm{CO}_{2}$-based Cardox $[8,9]$

- Sunburst penetration cone fracture [8]

- Diamond wire cutting $[6,10,11]$

- Mobile miner

- Continuous mining machine

- Roller cutting with activated cutters

- Activated rotary drag-bit cutting

- Drum cutting

- High-pressure water rock breaking

- Impact ripper

- Ballistic hammer

- Electric rock breaking via dielectric breakdown

- Plasma blasting

- High-frequency electric discharges in water

- Radial-axial splitting tool

\section{Technology Life Cycle}

Having sketched the background with regard to the role of explosives, and particularly detonators and initiation systems, in mines, we now turn our attention toward the 


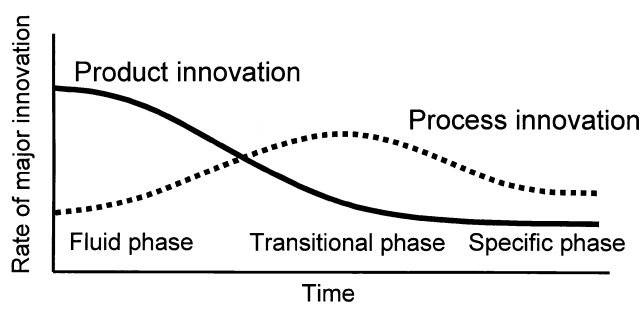

Fig. 1. Graphical representation of the Utterback-Abernathy model.

evolution of electronic initiation systems. The purpose of this investigation is to determine the status of the technology's maturity, and to use that information to guide the decision-making process with regard to the innovation strategy process.

The UA model of technological development $[12,13]$ is discussed in the literature and was adopted in this study for its simplicity and thoroughness as well as its ability to determine the nature of the short-, medium-, and long-term technology management challenges that have to be addressed. It provides a fundamental understanding of the typical phases a new technological innovation goes through as it develops from infancy to maturity. Although the UA model is described in elaborate detail in the references, it is useful to capture some of the basic thrusts of the model here to put the rest of the discussion into perspective. According to the UA model, the innovation process typically progresses in three phases, namely, the fluid phase, the transitional phase, and the specific phase. In the fluid phase, the product concept is undefined and the basis for competition is primarily product features. There is a subsequent high rate of product innovations, whereas process and manufacturing innovations take a back seat.

Eventually a dominant design emerges that stabilizes the product concept-this is the design that win the allegiance of the marketplace. Although the dominant design doesn't necessarily embody the best technical performance, it is "how the product is supposed to look and operate." The emergence of the dominant design is a watershed in the evolution of the product. Once the dominant design has been established, the transitional phase is entered. In this phase, the focus shifts to manufacturing competence, and consequently one finds an increase in the rate of process innovations and a decrease in the rate of product innovations. Finally, the product moves into the specific phase, where the rates of both product and process innovations decline. Figure 1 graphically illustrates the three phases of the UA model (after [12]).

It is important to distinguish between the concepts of "electronic initiation systems as the new dominant design in initiation systems" and "the characteristics of the dominant design in electronic initiation systems." The substitution issue relates to whether electronic initiation systems will replace the mature technologies (cap-and-fuse and shock tube) as the preferred initiation system. Our main focus, however, is on the characteristics that the dominant design in electronic initiation systems as a product class will exhibit.

The UA model is significant in that it explains differences in emphasis with regard to issues such as the nature of innovation, sources of innovation, the interplay between product and process innovations, the nature of research and development, the changing industry ecology, the shifting basis of competition, organizational control, and the vulnerability of industry leaders as the product evolves with time, specifically through the various phases Because of the different characteristics associated with each of the 
different phases, the management approaches and strategies will necessarily be different in each of the three phases. Hence it is important to identify which phase the technology is in and to develop and deploy an appropriate strategy.

There is substantive evidence to support the assertion that electronic initiation systems are still in the fluid phase of the UA model. There are a number of systems, each with a different product concept, and hence the notion of competition on the basis of product features is very evident. Each of the companies manufacturing electronic initiation systems has a unique product with its own distinct features, and each sincerely believes that it has a good solution that will address the perceived needs in a unique way and will give it a competitive advantage in the market. Some of the initial prototypes were crude and unreliable, but there have already been a number of iterations and changes to product specifications and characteristics during the development phase. Research was initially very important $[14,15]$, with all the companies spending significant resources to build the necessary knowledge base and to solve some difficult technical problems. It was realized that final product cost to the market would be critical, and most of the companies took this into consideration at the design stage, e.g., by developing custom ICs to minimize the number of components used in each detonator. As yet, no legal or industry standards for electronic initiation systems exist. The technology is significantly more expensive than currently used initiation systems (although the savings that result from using the new technology more than offset the additional expenses). There is high uncertainty about what the market wants. The market itself is hesitant, since it also faces high uncertainty as to its own needs, the effect that electronic initiation systems might have on operations, and consequently which system to choose. It is also interesting to note that many of the companies developing the new technology are outsiders to the blasting industry, and even those that were previously involved were all new to the detonator market. From an innovation strategy viewpoint, however, one of the most important indicators is that it is apparent that the dominant design in electronic initiation systems has not yet emerged. The emergence of the dominant design usually signals the onset of the transitional phase in the UA model.

Even though it would seem that electronic initiation systems are still in the fluid phase (especially since the dominant design hasn't yet emerged), there are also a number of similarities to the transitional phase of the UA model. The mode of production has already started to shift from general manufacturing tools to specialized equipment, and islands of automation are evident in some factories. In fact, several companies are seeking economies of scale by setting up production facilities to manufacture the electronic detonators on a large scale. This has resulted in a number of organizational changes: e.g., employing more administrative personnel and marketers. Product improvements have become mostly incremental and focused on eliminating problems.

The evolution of electronic initiation systems seems to follow the general UA model for assembled products quite well, but there are also a number of differences between the development of this technology and the theoretical pattern of the classical UA model; it is useful to explore these.

Since the new technology yields a considerable performance improvement (e.g., reduced stope width, improved face advance, and improved muck pile distribution), the price/performance ratio of the new technology is markedly better-in contrast to conventional wisdom, which holds that the price/performance ratio for a new technology typically is poorer initially than the existing technology and becomes the basis of competition only in the later phases of the UA model [12]. Furthermore, electronic initiation systems were specifically designed and developed for the mass market, and not for 
limited application in a niche market. This has led to the introduction of specialized equipment and automation at a much earlier stage than is usual for innovations. Very few improvements have resulted from user feedback or from lead-user innovations [16]. As yet, there has not been a visible competitive response from the old technologies by way of dramatic performance improvements or price reductions [15, 17]. There have been no significant new entrants to the market for the past few years, mainly because of high entry barriers, such as the large investment needed over a number of years.

There are a number of reasons why electronic initiation systems have not followed the classical UA model exactly. In the first place, the conservatism of the mining industry, with its focus on cost, as well as the high safety standards that have to be maintained in the detonator industry, has obliged the manufacturers of electronic initiation systems to develop a much more technologically advanced detonator before its commercialization than would normally have been the case. Further, the large volume of detonators that have to be manufactured (to exploit economies of scale) has led to a stronger emphasis on the manufacturing process and associated process innovations early in the life cycle of the product. It is mainly because of these two factors that some of the characteristics of the transitional phase are present while the product itself seems to be predominantly in the fluid phase. However, the mining industry's conservatism and resistance to change have caused the commercialization and diffusion of electronic initiation systems to progress more slowly than the manufacturers had anticipated. Many of the characteristics of the fluid phase have therefore not been experienced yet, such as changes in competitive leadership and market shares.

It is suggested that the UA model can be improved or refined by accounting for cases where there are strong pressures that drive an increase in the rate of process innovations before the dominant design has fully emerged. Although there are no hard and fast rules with regard to the switch from one phase to the next, it would seem that the boundary between the fluid and transitional phases can be more diffuse, specifically with regard to the manifestation of process-related elements of the transitional phase in the fluid phase. The emergence of flexible manufacturing and mass customization [18] will no doubt contribute to this notion. The implications of such a scenario are that the development process will be more focused on design for manufacturing, that the manufacturing process will receive attention earlier on in the life cycle than would normally be the case, and that user feedback should be used to a greater extent through all the stages of development.

\section{Emergence of the Dominant Design}

Having briefly put the evolvement of electronic initiation systems into perspective with regard to the bigger picture of the innovation process as exemplified by the UA model, we can conclude that the next significant issue to be resolved in the life cycle of the innovation is the emergence of the dominant design-and that this is where managerial attention should focus from an innovation strategy viewpoint.

The emergence of a dominant design is one of the most important and dramatic events in the life of a technology and has a significant impact on the rate of product and process innovations, as well as on the market and on the industry structure [12]. Lee et al. defined a dominant design as "the distinctive way of providing a generic service or function that has achieved and maintained the highest level of market acceptance for a significant amount of time" [19]. A dominant design enforces or encourages standardization, leading to mass production and economies of scale [20]. Competitors unable to adjust to the dominant design have either to be satisfied with a niche of the 
market or to withdraw entirely. In the words of Tushman and Anderson, "it heralds the end of the era of ferment and introduces the era of incremental change" [21]. The dominant design marks the end of the fluid phase and introduces the transitional phase [13].

Empirical evidence suggests that the emergence of a dominant design, although not irreversible, is highly directional. The market risk involved with subsequently introducing a new product that, albeit functionally better, differs from the dominant design is extremely high. A dominant design is often not the technologically superior design and is usually the result of a complex interplay between technological factors and user demands as well as political, social, and economic factors. This makes it very difficult to anticipate in advance what the dominant design's characteristics will be and consequently how to exert influence on its characteristics. That this process may be difficult and fraught with pitfalls does not detract from the inherent need to do so.

Obviously the issue of dominant design in electronic initiation systems is highly relevant to the entire mining industry, including the manufacturers of the mature technology, the manufacturers of the emerging technology, and the users. It is apparent that the advantages associated with the new technology are considerable when compared with shock tube and cap-and-fuse systems. Barring an even better technology and allowing for ever-present external factors, a strong case be made, from technological as well as cost/benefit viewpoints, to support the emergence of electronic technologies as the preferred initiation systems for blasting applications, at least in narrow-stope mining. However, the issue is not only whether electronic initiation systems will replace the older technologies and become the preferred technology for initiation systems, but also what will be the nature and characteristics of the dominant design that may emerge among the contending systems that incorporate this new technology. The latter is the main focus of our discussion.

The competing electronic initiation systems differ widely with regard to characteristics, ranging from detonators with conventional pyrotechnic delays whose inter-hole delay is controlled by uncomplicated electronic blast controllers, to systems with electronic detonators that are fully computer-controlled. Historical evidence suggests that the market will not be able to tolerate such a variety of systems and will gravitate to a particular set of features synthesized from the individual product variants to form a dominant design. Similar pressures will in all probability also lead electronic initiation systems to assume certain common attributes that would constitute the eventual dominant design.

Although many factors have been identified as having influenced the emergence of dominant designs, the process is still poorly understood. It is very evident, though, that it is a complex process. Many authors have adopted a "black box" approach to the emerging process-regarding the dominant design as the result of an interplay between technological and non-technological factors, whose influence can often be determined only with the wisdom of hindsight. Yet it is the dominant design that has often sealed the fate of an otherwise competent competitor, causing fortunes to be made or lost. Although it is impossible to accurately determine the outcome beforehand, most companies would like to reduce their uncertainty in this regard, or at least know how to influence the emergence of the dominant design in their favor. If a company understands how and why an innovation becomes dominant, it can strategically plan its resource allocation and make informed decisions to appropriate the maximum benefit from its own and others' innovations. A framework is needed to understand the factors that influence the emergence of a dominant design and to provide a strategic approach 
TABLE 1

Factors Influencing the Emergence of a Dominant Design

$\begin{array}{ll}\text { Technological factors } & \text { Technological feasibility } \\ & \text { Technical capability } \\ & \text { Rate of technological change } \\ & \text { Momentum of the established practice } \\ & \text { Marketing } \\ & \text { Strong brand name } \\ & \text { Distribution network } \\ \text { Market factors } & \text { Network externalities } \\ & \text { First-mover advantages } \\ & \text { Demand-side factors } \\ & \text { Supply-side factors } \\ & \text { Ease of use } \\ \text { Economic factors } & \text { Resistance to change } \\ & \text { Communication between producer and user } \\ \text { Social and behavioral factors } & \text { Current standards and industry regulations } \\ \text { Standards and regulations } & \text { Government regulations } \\ & \text { Industry standards and committees } \\ & \text { Safety, health, and environmental concerns } \\ \text { Political factors } & \text { Sociopolitical forces } \\ \text { Strategic factors } & \text { Interactive learning } \\ & \text { Powerful user } \\ & \text { Powerful producer } \\ & \text { Alliances } \\ & \text { Complementary assets } \\ & \text { Patents } \\ & \text { Appropriability } \\ & \\ & \\ & \end{array}$

to the whole issue. Lee et al. have recently developed a useful framework of factors that influence the emergence of the dominant design [19].

The study of electronic initiation systems provides us with additional insights on issues that may play a role, not only in this particular case, but perhaps also in a wider context. In this study we use a more extensive framework that provides a comprehensive view of the factors influencing the emergence of a dominant design (see Table 1). These factors are discussed below with specific reference to electronic initiation systems.

\section{TECHNOLOGICAL FACTORS}

The technological feasibility of an innovation can be considered to be a combination of those conditions of functionality, reproducibility, and superiority (or at least parity) that an innovation needs to succeed in the marketplace [12]. These conditions have to be met before the dominant design will emerge, and they are all present in the case of electronic initiation systems. The presence of these conditions favors the eventual preferment of electronic initiation systems over pyrotechnic and shock tube systems but will not necessarily contribute to the eventual dominance of any particular product or product characteristic.

Tushman and Rosenkopf contend that in the case of simple assembled or nonassembled products, the dominant design will be predominantly determined by the innovation's technical capability [22]. For more complex systems this becomes a necessary but insufficient condition. In this regard it should be noted that the technical capability of electronic initiation is well above that of other initiation systems. 
TABLE 2

Technical Parameters that May Be Incorporated into the Dominant Design

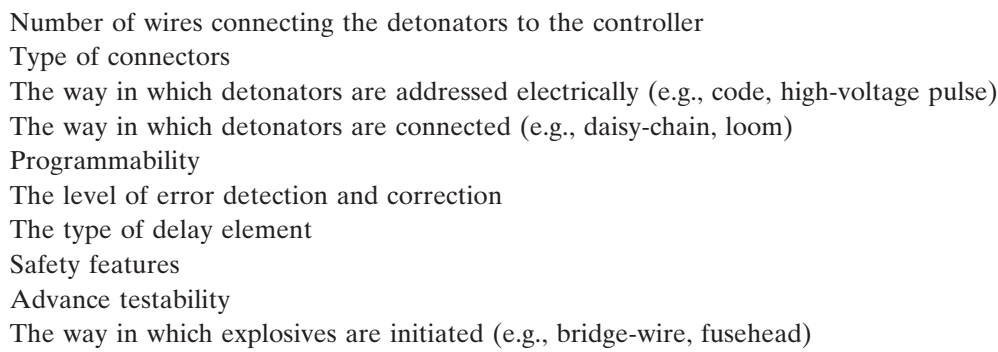

Table 2 lists some of the technical parameters that may be incorporated as characteristics of the dominant design for electronic initiation systems. It is possible that a dominant design may emerge for the electronic detonator itself, which is a subsystem of the larger electronic initiation system. Since the detonator is only a simple assembled product, technical capability will probably play a crucial role in determining the characteristics of the dominant design.

When the rate of technological change of an innovation is very high, this will have a negative effect on the emergence of a dominant design. The innovation might still be in the fluid phase, and users will be unwilling to commit themselves to a particular design when the number of alternatives is too high [19]. For electronic initiation systems, the market might well perceive a high rate of technological change as companies commercialize their products and introduce them to the market. A paradoxical situation might result where manufacturers are pressured to consolidate differences between their products before most users will adopt the technology. Yet at the same time they will be dependent on sufficient users' expressing their preferences and adopting the technology. This places negative pressure on the technology's becoming dominant, but positive pressure on the emergence of a dominant design within the new technology.

The momentum of the established practice can retard the emergence of a dominant design when the old technology is firmly entrenched. People are often used to doing things a certain way and may not want to change or see the need to change. This factor will definitely have a negative impact on electronic initiation systems' becoming dominant, since conventional systems have been used for decades. The conservatism in the mining industry has been noted, not only that of management, but also that due to the miners' resistance to technological change. Most miners are unwilling to change the way in which things have been done traditionally, and it might take considerable time to build the necessary confidence in the new technology. Any accidents or an initial or temporary reduction in productivity due to the use of electronic initiation systems will only strengthen this perception. This factor's influence can be reduced by making the operation of the detonator as similar to the conventional systems as possible.

\section{MARKET FACTORS}

Perhaps one of the most important factors in the success of any technological innovation is the marketing thereof [23]. Marketing will play an important role in determining the eventual characteristics of the dominant design in situations where there are a number of significantly different designs on the market, as with electronic initiation systems, and in promoting the use and acceptance of the new technology. The successful marketing of a particular competitor's product features might have an 
influence on the incorporation of those features into the dominant design. This is especially relevant where standards still have to be determined and compatibility with other systems may become an issue.

A strong brand name that enters the market will have a strong power base and may strongly influence the dominant design in a particular technology. However, it seems doubtful that this will create a significant competitive advantage for any manufacturer of electronic initiation systems to influence the dominant design in its favor.

The distribution network that a particular firm uses can have a major influence on the availability of its product. An effective and efficient distribution network will go a long way toward establishing a significant, if not dominant, market share. The opinion of the market leader has more weight than the opinions of other players, giving it an opportunity to exert influence on the emergence of the dominant design in its favor. However, this is unlikely to play an important role for electronic initiation systems, since most of the developers have production facilities that can easily cope with the expected demand of electronic detonators.

Network externalities do not seem to play a significant role. They exist when a product's value to the user increases as a function of its adoption by other consumers [19]. The higher the dependence on network externalities, the more important they become in the emergence of the dominant design, since the need for compatibility will be greater.

There are some first-mover advantages that have an influence on the emergence of a dominant design. If a firm can be the first to market a product of fair quality for a period of time (so that a lack of quality or technical performance will not hinder its diffusion too much), enough users may adopt it so that switching costs will prohibit them from using competitive products. Buyers that have imperfect information regarding product quality may continue using the first product they encounter that performs the job satisfactorily [24]. This will improve the first mover's power base in the market, and hence his influence on a dominant design. It can define the attributes that are perceived as important. However, the conservatism of the mining industry, and the small market share that electronic initiation systems have ben able to capture thus far, reduce the probability that these companies will sustain any first-mover advantages or power bases that they may have built up.

\section{ECONOMIC FACTORS}

Economic factors that promote the emergence of a dominant design can be divided into demand-side and supply-side forces [19]. On the demand side, the mining industry wishes to minimize its search costs (e.g., assessing alternative products) and to increase purchasing efficiency, as well as to reduce its risk by lowering switching costs. A dominant design will reduce product class confusion and the possibility of switching costs. Because of the high uncertainty in the market, the mining industry will probably rather wait until the manufacturers have settled on some kind of industry standard for detonators before purchasing an electronic initiation system. The manufacturers will, after a while, tend to adopt certain aspects of their competitors' products that will enhance the attractiveness of their own products.

On the supply side, the manufacturers will seek improved efficiency through scale economies allowed by the emergence of a dominant design. They will do so by trying to limit the variety of systems offered and by simplifying the technical information needed for efficient production. A dominant design will also simplify customer communication and lower inventory requirements. By optimizing some of these parameters 
beforehand, a producer might influence the nature of the dominant design in its favor, especially if competitors have more complex products.

SOCIAL AND BEHAVIORAL FACTORS

A product's ease of use relative to its competitors can play an important role. Detonators that easier to operate, especially if their operation resembles conventional systems, stand a higher chance of being accepted and adopted by the miners. A particular means of operation will in all probability form part of the eventual dominant design.

The user's resistance to change often causes a technological innovation to diffuse more slowly than expected, thereby increasing the period before a dominant design will emerge. Resistance to change is an infamous characteristic of the mining industry, especially at the grassroots level. In fact, the lack of training needed to familiarize the miners, who are stuck in the traditions and habits of a century of mining, with newer methods is cited as one of two primary reasons for one company's apparent failure in the market (the other being the lack of a comprehensive marketing program) [25]. It is possible that a paradoxical situation will arise where the resistance to change is so high that the mining industry will be unwilling to invest in electronic initiation systems before a certain design becomes dominant ("we will rather wait until the market sorts itself out"), while the manufacturers' conflicting opinions of what the market wants remain unresolved until the market gives them some directions.

\section{STANDARDS AND REGULATIONS}

The new technology might initially have to comply with current standards or industry and government regulations that implicitly or explicitly relate to the mature technology, even though they might not be applicable if the innovation approaches the problem in a different way. This may hinder the new technology from becoming dominant until it can break the restrictions of these regulations. It will also hinder the emergence of the dominant design, since the dominant design might eventually include some characteristics that the current standards do not permit. In South Africa, for example, there is still some legislation on blasting (unchanged for more than 30 years) that imposes restrictions applicable to fuse and igniter cord systems (although it does make provision for certain exemptions) and as such does not take account of a newer technology such as electronic initiation systems.

Industry committees and international standardization commissions are often involved with setting certain standards to regulate and stabilize the industry. They work to enhance compatibility between different products and within systems. A working group has been formed at the South African Bureau of Standards to draw up a code of practice for the use of electronic initiation systems that will eventually lead to new legislation regarding the use of electronic initiation systems. It is possible that this legislation will enforce certain standards that might have an influence on the characteristics of the dominant design.

\section{POLITICAL FACTORS}

Sociopolitical forces often have a significant influence on the development of a dominant design. However, they are difficult to predict, quantify, or control, even though they can often be identified beforehand. To quote Lee et al.: "Customers, suppliers and governments - national, regional and local - may have substantial interests in, and preferences for, particular designs. They may also have reasons to support or oppose the general move to standardisation. Standards may be influenced by dominant producers, powerful users or groups of users, industries, and governments. The many forms of 
government research, industry, and trade policies and actions can greatly affect innovation, development, and commercialisation through their impact on resources and the cost and rules of doing business" [19].

For electronic initiation systems, the increased output per blast might imply that fewer miners will be employed, in which case the labor unions could exert pressure on the mines not to adopt the new technology. As a productivity incentive to the miners, the mines can offer them a bonus proportionate to the amount of rock mined in excess of a certain threshold. Once electronic initiation systems are used correctly, it should become easier for the miners to receive this bonus. This may also have a negative influence, however, in that it may induce miners from neighboring sections or shafts to disrupt the electronic initiation systems. However, there is also a possibility that higher bonuses due to an increase in productivity could also act as an incentive for other sections to follow suit. In that case they would have a positive impact on electronic initiation systems' becoming the dominant design. The manufacturers should therefore market the new technology to the miners in such a way that the productivity incentives will work in both the miners' and the technology's favor.

\section{ORGANIZATIONAL ISSUES}

The interactive learning between organizations [19] plays an important role when organizations follow the lead of others and develop similar products either by themselves or through a license agreement. The probability that some of the characteristics or specifications of the product being copied will be taken up in the dominant design is increased by such actions. Imitation may well signify that the emergence of a dominant design is nigh. This factor will begin to play a role in the detonator industry only when more competitors begin to vie for a share of the market.

A powerful user may be able to dictate a standard [22], for example when the public electric utility company ESKOM introduced the STS standard for prepaid electricity meters in South Africa [26]. Although ESKOM does not produce the meters itself, it does expect all manufacturers of them to conform to the STS communication protocol.

A powerful producer may sometimes be able to dictate the specifications of a dominant design, especially where it is the only relevant vendor [24]. For example, IBM was able to introduce its System/360 even without maintaining retro-compatibility, simply because it was the only important producer of business computers at the time [27]. There are, however, no particularly powerful users or producers among the mines or the manufacturers of electronic initiation systems that will be able to dictate a standard or specifications for the dominant design. Finally, a group of firms may form an alliance around a particular standard or certain aspects of electronic initiation systems [22].

\section{STRATEGIC FACTORS}

A firm might be able to protect its technological innovation with a number of patents in such a way that other companies find it difficult to invent competitive products without paying license fees. In such a situation a firm will have a very strong influence on the features of the dominant design by capturing a number of them in its patents. It is generally agreed among the manufacturers of electronic initiation systems, however, that in this case patents do not offer many advantages and can be circumvented. Nevertheless, some aspects of the eventual dominant design, such as the connectors used, might be enshrined in a patent — which will be to the advantage of its owner.

Appropriability is the ability of an innovator to protect its innovation from imitation by competitors [19] and to capture the profits generated by the innovation [28]. Appropri- 
ability is dependent not only on solid patents, copyrights, or trademarks, but also on a secure research and development and production environment. If both these factors are high, the diffusion and use of proprietary information will be slow, and the firm may enjoy a period of time in which it does not have to compete with similar innovations. The degree of appropriability for electronic initiation systems is not very high. Anderson and Tushman hypothesized that in regimes of low appropriability, a single dominant design will emerge following each technological discontinuity [29]. They also argued that a dominant design may not emerge in regimes of high appropriability where the competition process is artificially forestalled. If this is true, it increases the possibility that a dominant design will emerge within electronic initiation systems.

\section{Application to Managerial Decision Support}

In the previous sections the historic evolvement of electronic initiation systems was discussed within the framework of the UA model. From a technology and innovation strategy point of view, the question that arise, however, is what can be learned from the assessment of the evolvement off electronic initiation systems that can be applied to support managerial decision making with regard to strategies in initiation systems for mines. We now apply the UA model in an anticipatory manner to this end.

An analysis within the UA model indicates that electronic initiation systems are still predominantly in the fluid phase and that the dominant design has not yet evolved. Given that the emergence of a dominant design is such an important issue in the life cycle of a technology and that it has a very important impact, from a managerial viewpoint, on the businesses that rely on that technology, an assessment of the factors that influence the emergence of the dominant design should be considered very important and urgent with regard to innovation strategy.

Although some characteristics of the transitional phase of the UA model are already evident, indications are that more will emerge. Technological progress will probably happen through material and component substitution to reduce cost and improve efficiency, as the focus of research and development will be on incremental innovations to the different components and subsystems. Even though the per-unit cost of the electronic detonators is still high, the cost/benefit ratio and increases in productivity that can be attained with electronic initiation systems are substantial.

There will also be improvements to the manufacturing process as the manufacturers strive to reduce the cost of production and increase output. As with many emerging technologies that have progressed somewhat on the technological trajectory, it would be safe to assume that per-unit costs will drop even more, particularly when the manufacturing processes become more streamlined and economy-of-scale effects take hold. Automation of the manufacturing process will eventually be optimized, and specialized equipment will be employed to a greater extent to accomplish this.

Competition is expected to be stiff in the light of the large market and the number of different systems available, each one with its own advantages and disadvantages. Initially the strongest factors influencing competition will be the systems' cost, functionality, and ease of use, although safety, reliability, and flexibility will be relevant as well. It is almost certain that at least one or two of the competitors will not be able to meet the market's expectations and will have to withdraw from the market-probably after the emergence of the dominant design.

Initially, hybrid systems may gain more acceptance because of their similarity to the currently used systems (which will reduce the resistance to change and the amount of time and money spent on retraining workers), as well as their reduced cost and 
complexity. However, these systems do not offer the same flexibility and productivity as the fully electronic systems. In the longer term the more sophisticated, fully electronic initiation systems will probably dominate the market because of their enhanced performance and cost-effectiveness. Manufacturers of hybrid systems would do well to keep an eye on the way in which the market develops and start developing their own fully electronic initiation systems well ahead of time.

Once the technology gains more widespread market acceptance, the mines may find that some changes will have to e incorporated, for its is a well known phenomenon that new technologies necessitate organizational changes. For example, fewer laborers may be needed to clear the rubble of the muck-pile after the blast, since it will be less scattered, and holes will be easier to drill if the stope face is more evenly fractured. Because of the increased amount of ore mined as well as the increase in the gold recovery rate [30], new bottlenecks may surface. The processing mills, for example, may not have sufficient capacity. In the long run, other equipment and processes not directly related to blasting will probably be improved to make full use of the advantages that electronic initiation systems bring.

Given the current life cycle status of electronic initiation systems, one of the most important issues to consider is which product features will actually be incorporated in the dominant design. Which features will become part of the de facto or de jure standard? As is the case with many dominant designs, it will probably be a synthesis of the competing pre-dominant design products.

Considering the importance attached to the way in which the detonators are connected (in the sense that this will reduce the resistance to change and reduce the amount of retraining the workers will have to undergo), the dominant design will probably incorporate a standardized method of connection. This includes both the way in which the detonators are physically connected to the harness and the configuration of the harness (daisy-chain ${ }^{1}$ or loom). In fact, it is quite possible that the current way in which the detonators are connected in the cap-and-fuse system has already become, or at least has laid the foundation for, the dominant design in electronic initiation systems. Once the dominant design emerges, it will be required that all systems operate in a similar way, regardless of their other features. Improvements to the linkage between the detonators and the blast controller are also expected: for example, a coding system that offers increased feedback, security, and control.

The type of delay element used and the way in which the detonators are addressed electrically (code, high voltage, etc.) will probably also be incorporated as a characteristic of the dominant design. However, since these features are less visible and tangible to the end user (i.e., the miner), the chance that these features will become part of the dominant design is not as strong as for the means of connection. The safety features used, albeit important, will not necessarily require conformity between the different systems, as long as each system measures up to certain minimum specifications. The way in which the explosives are initiated (bridge-wire, fuse head, etc.) stands only a small chance of becoming part of the dominant design — probably only if it has an impact on performance.

It should be kept in mind that not all features have to become dominant in the same period of time-as technological progress (and market expectations) enhances

\footnotetext{
${ }^{1}$ In the case of a daisy-chain connection, the harness is simply made of the detonators connected to one another in serial fashion.
} 
the systems, new features will become important that may not previously have been considered as important.

The influence of non-blasting techniques is very difficult to determine. Even though some of these techniques have been successfully applied in particular niche markets [8], most of them do not seem viable to exploit further. However, it is well known that a radical technology often enters via a niche market where it is able to improve itself and eventually capture a significant share of the large market [12,15]. It is therefore entirely possible that further technological advances may improve non-blasting techniques to such an extent that they will threaten the entire blasting industry.

\section{Conclusions}

The mining industry in South Africa contributes significantly to the GDP and also to foreign exchange earnings of the country. The narrow-stope gold mining industry is currently under severe cost pressures, and hence there is renewed interest in technological innovations that may bring increases in productivity and profits. Electronic initiation of blasting is such an emerging technology and thus warrants serious consideration and assessment. Given the significant economic impacts that are at stake it is necessary, from a technology strategy viewpoint, to assess this possibility and the factors that may influence the development and evolution of electronic initiation systems. The UA model shows that the evolution of electronic initiation systems is still very much in the fluid phase and that the dominant design has not yet emerged. Managerial attention should thus be focused on factors that will influence the emergence of the dominant design. An assessment of the literature shows that several of the factors that have in the past influenced the emergence of dominant designs can very well play a role here, but that there are others as well. It is concluded that a strong case can be made that electronic initiation systems may very well become the preferred initiation system in the mining industry in South Africa. However, the factors that influence the emergence of the dominant design in electronic initiation systems must be addressed in a focused manner.

\section{References}

1. Statistical Tables, Chamber of Mines of South Africa, 1996.

2. CSIR: Techno Brief 6(2), 6 (1996).

3. Mining, A Financial Mail Special Survey (October 13, 1995).

4. Brinkman, J. P.: Potential Benefits of Alternative Initiation Systems for Gold Mining, COMRO Research Report No. 16/89 (May 1989).

5. Childs, J., and Watson, J. T.: Digidet: A New Approach to Electronic Delay Blasting, Coal 26, (1996).

6. Business Day (March 13, 1995).

7. Mining Weekly (16 February 1996).

8. Mining Weekly (17 February 1995).

9. Blasting Cardox-More Heave than Blast, World Mining Equipment 19(4), 50 (1995).

10. Mining Weekly (3 March 1995).

11. Mining Weekly (10 March 1995).

12. Utterback, J. M.: Mastering the Dynamics of Innovation. Harvard Business School Press, Boston, 1994.

13. Utterback, J. M., and Abernathy, W. J.: A Dynamic Model of Process and Product Innovation, Omega 3(6), 639-656 (1975).

14. Foster, R. N.: Timing Technological Transitions, in Readings in the Management of Innovation. 2nd ed. M. L. Toshman and W. L. Moore, eds., Harper Business, 1998, pp. 215-228.

15. Foster, R. N.: Innovation: The Attacker's Advantage. Summit Books, New York. 1986.

16. Von Hippel, E.: The Sources of Innovation. Oxford University Press, New York, 1988.

17. Cooper, A. C., and Schendel, D.: Strategic Responses to Technological Threats, Business Horizons 19(1): 61-69 (1976).

18. Pine, B. J.: Mass Customization. Harvard Business School Press, Boston, 1993. 
19. Lee, J. R., O’Neil, D. E., Pruett, M. W., and Thomas, H.: Planning for Dominance: A Strategic Perspective on the Emergence of a Dominant Design, R\&D Management 25(1), 3-15 (1995).

20. Utterback, J. M., and Suárez, F. F.: Innovation, Competition, and Industry Structure, Research Policy 22, 1-21 (1993).

21. Tushman, M. L., and Anderson, P.: Technological Discontinuities and Organizational Environments, Administrative Science Quarterly 31, 439-465 (1986).

22. Tushman, M. L., and Rosenkopf, L.: Organizational Determinants of Technological Change: Toward a Sociology of Technological Evolution, Research in Organizational Behaviour 14, 311-347 (1992).

23. Schnaars, S. P.: When entering growth markets, are pioneers better than poachers?, Business Horizons March-April, 27-36 (1986).

24. Farrell, J., and Saloner, G.: Competition, Compatibility and Standards: The Economics of Horses, Penguins and Lemmings, in Product Standardization and Competitive Strategy. H. L. Gabel, ed., Holland, Amsterdam, 1987, pp. 1-21.

25. Blast that Detonator!, Financial Mail (February 16 1996).

26. Smit, F. C., and Van Hoving, W. J.: Factors that Influenced the Diffusion of Prepaid Electricity Meters-The Manufacturer's Perspective. Research report, Institute for Technological Innovation, University of Pretoria, 1996.

27. Fisher, F., McGowan, J., and Greenwood J.: Folded, Spindled and Mutilated: Economic Analysis and the IBM Case. MIT Press, Cambridge, MA, 1983.

28. Teece, D. J.: Profiting from Technological Innovation: Implications for Integration, Collaboration, Licensing and Public Policy, Research Policy 15, 285-305 (1986).

29. Anderson, P., and Tushman, M. L.: Technological Discontinuities and Dominant Designs: A Cyclical Model of Technological Change, Administrative Science Quarterly 35, 604-633 (1990).

30. Bock, I. E.: Selective Blast Mining, Symposium of the South African Institute of Mining and Metallurgical Engineers, Pretoria (June 11, 1996).

Received 28 November 1997; revised 12 January 1998; accepted 13 January 1998 